\title{
The Impact of a Didactic Strategy using Technology to Strengthen the Learning of Mathematics
}

\author{
Lizzeth Navarro-Ibarra ${ }^{1}$ \\ Omar Cuevas-Salazar² \\ Instituto Tecnologico de Sonora, Mexico. \\ 'Email:Lizzeth.Navarro@gmail.com Tel:526449978639 \\ 'Email:omar.cuevas@itson.edu.mx Tel:526441222319
}

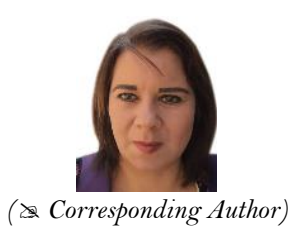

Abstract

The didactic strategy of this study consisted of the implementation of virtual practices for learning Mathematics at the university level. The objectives established to evaluate the impact of the strategy were to determine the contribution of these virtual practices and identify their effect on students' academic performance. The strategy was carried out in the course Fundamentals of Mathematics, for first semester students in the Engineering programs at the Sonora Institute of Technology and 1,144 students participated between August 2018 and May 2019. The results proved that the students who participated scored higher in the course than those who did not participate. A dependency ratio was also found between the variables of students' final grades in Fundamentals of Mathematics and the number of virtual practices they had carried out. The conclusion is that the didactic strategy significantly improves the passing rate and academic performance in the subject of Mathematics for which it was implemented.

Keywords: e-learning, Mathematics education, Self-learning, Undergraduates, Virtual practices, Didactic strategy.

Citation | Lizzeth Navarro-Ibarra; Omar Cuevas-Salazar (2021) The Impact of a Didactic Strategy using Technology to Strengthen the Learning of Mathematics. Journal of Education and e-Learning Research, 8(1): 90-96.

History:

Received: 7 August 2020

Revised: 12 October 2020

Accepted: 6 January 2021

Published: 28 January 202

Licensed: This work is licensed under a Creative Commons

Attribution 3.0 License (oc)

Publisher: Asian Online Journal Publishing Group
Acknowledgement: Both authors contributed to the conception and design of the study.

Funding: This study received from PROFEXCE 2020 resources.

Competing Interests: The authors declare that they have no conflict of interests.

Transparency: The authors confirm that the manuscript is an honest, Transparency: The authors confirm that the manuscript is an honest,
accurate, and transparent account of the study was reported; that no vital accurate, and transparent account of the study was reported; that no vital
features of the study have been omitted; and that any discrepancies from the features of the study have been omitted;
study as planned have been explained.

Ethical: This study follows all ethical practices during writing.

\section{Contents}

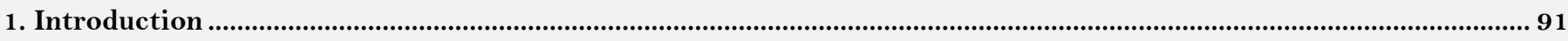

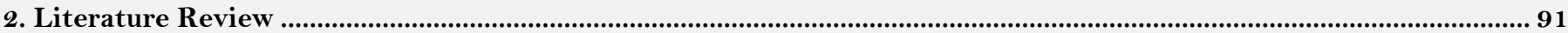

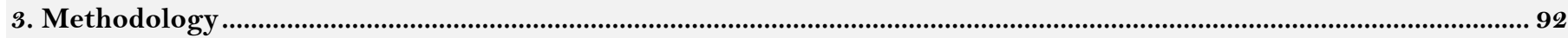

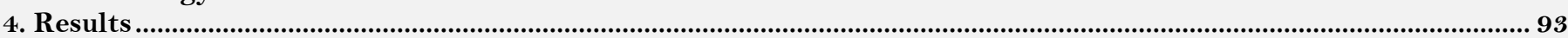

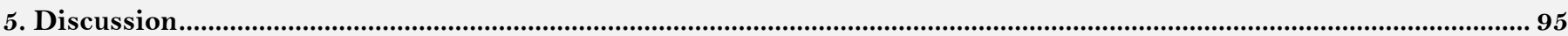

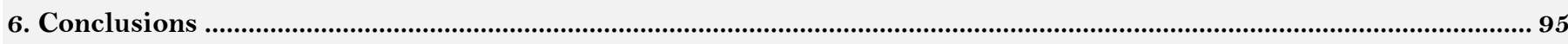

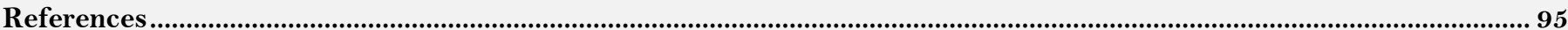




\section{Contribution of this paper to the literature}

This study contributes to existing literature by evaluating the impact of the strategy was to determine the contribution of these virtual practices and identify their effect on students' academic performance.

\section{Introduction}

Education is a human right which is essential for defending and preserving other rights. However, high-quality education is needed and to achieve this, it is necessary to master reading, writing, calculus, analytical skills, and problem solving, as well as social skills. On the other hand, the focus of learning should be on the development of life skills to decrease poverty through better jobs (UNESCO, 2015).

Kollosche (2018) mentions that one of the advantages of learning mathematics is to provide students with skills for analyzing and solving problems which can later be applied to their private and professional lives. Other skills which are developed are concentration, alacrity, and precision.

Mathematics is a broad subject which requires reasoning, creativity, the ability to make connections, and the ability to interpret methods. Therefore, Boaler (2016) states that students will achieve a greater commitment to mathematics if the various ways in which people see mathematics and the ways they may take to solve a problem are encouraged within the problems.

Recently, research has been conducted into the effect studying mathematics has on students. The general tendency indicates, nevertheless, that the enjoyment of learning mathematics decreases over the years. It is necessary to develop new teaching approaches which stimulate a positive relationship with mathematics, without affecting students' understanding of its concepts (Pitta-Pantazi \& Leikin, 2018).

There is a prevalent idea in society that problem-solving skills in mathematics are a sign of intelligence and that not having that ability means that a person is not intelligent. This concept leads to difficulty in mathematics affecting students' self-confidence, which impedes their learning (Boaler, 2016). In a recent study carried out in Norway, it was found that it is possible to change students' mentality with respect to their belief in their learning skills in general, as well as their perseverance and commitment to mathematical problem solving (Bettinger, Ludvigsen, Rege, Solli, \& Yeager, 2018).

Since the beginning of the $21^{\text {st }}$ century there has been a change in the philosophy of education and approaches to learning. Teaching, and the spaces where it is carried out, must be more flexible in order to comply with the interests and needs of a wider range of students. Additionally, the development of the skills and knowledge which are vital for the new century must be included. Information and communication technology (ICT) has the potential to adapt these new requirements to present-day education (Fox-Turnbull, 2017).

Henderson, Selwyn, and Aston (2017) state that digital technology is an important element in university education and the way in which students carry out their studies. However, digital technology is not transforming or changing teaching notably. While students are using technology in their studies, they are not really taking advantage of its potential to the fullest.

Technology-supported learning can improve learning outcomes, when based on a systematic redesign of the curriculum. The evidence of fifteen years of projects in the United States on the use of technology in teaching indicated that on average $72 \%$ of the students showed improvement while $28 \%$ showed no change (Davies, Mullan, \& Feldman, 2017).

John (2008), as well as Davies et al. (2017) mention that the dilemma is no longer whether we should invest in technology in order to increase learning, but rather in what way ICT should be included in learning in order to achieve the best results for students. It is in the face of this concept that we have established the questions and objectives of our research.

\subsection{Research Questions}

To what extent does the implementation of an integral didactic strategy based on virtual practices contribute to students' learning of mathematics at the undergraduate university level?

What effect does an integral didactic strategy based on virtual practices have on students' academic achievement?

\subsection{Research Purpose}

To determine the contribution of an integral didactic strategy based on virtual practices to university students' learning of mathematics.

To identify the effect an integral didactic strategy based on virtual practices has on students' academic performance.

\section{Literature Review}

A study was carried out in the United Kingdom involving 389 children of between 4 and 5 years of age in order to improve their performance in Mathematics. Twelve schools participated in the study during the last twelve weeks of the school year. The participants were chosen randomly and were divided into three groups. In the control group the students were taught using traditional methods. In the other groups, two types of intervention were trialed using interactive digital applications which used the educational psychology method of combining direct instruction with play. In one of the trial groups, the children received traditional instruction during lesson time and used interactive digital applications during extra time. In the other trial group, the participants used interactive digital applications during their normal class sessions, optimizing the teacher's instruction. The results show greater learning in the two trial groups than in the control group which had used traditional teaching exclusively. Moreover, there was no significant difference between the two intervention types, showing that interactive digital applications may be included within the curriculum (Outhwaite, Faulder, Gulliford, \& Pitchford, 2019). 
Pellegrini, Lake, Inns, and Slavin (2018) carried out research on 78 mathematics programs for basic education whose aim was to improve achievement. These programs were implemented in the United States, the United Kingdom, Canada, and Germany. Of these, 14 used technology as their didactic proposal. In most cases a small positive impact was achieved. The average size of the effect was +.07 . However, they concluded that in future longterm studies more significant differences could be achieved.

A study was conducted in Sweden to determine the effects of tablet use on second graders' learning of mathematics. 283 students who had low levels of academic performance participated in the study. Four groups were randomly assigned. Aside from the control group and another experimental group in which a study in reading was being carried out, in the third group a mathematics intervention with a didactic proposal was used, and in the fourth, besides the didactic proposal, short-term memory training was added. The mathematical content which was covered in the proposal was arithmetic appropriate for the middle of the school year. The results showed that in the control and reading groups there was no improvement in mathematical academic achievement. In contrast, in group three, as well as in the group where short-term memory training was included, improvement in academic achievement was reached with a meaningful effect size. However, the effect decreased over time (6 months) and decreased even more at 12 months. Another relevant aspect which arose was that the students with a lower IQ were shown to have benefited the most from the didactic proposal (Hassler, Klingberg, \& Ghaderi, 2018).

The use of mobile devices for learning mathematics was studied in primary schools in Scotland. The study involved 52 students between 9 and 11 years old. The experimental group was made up of 24 students, while there were 28 students in the control group. The study was developed over 12 sessions, once a week for three months. The students from the experimental group carried out activities with mobile devices (tablets) which allowed them to relate mathematical concepts to the environment by using the camera, sensors, and connectivity to the internet. In the control group, teaching was carried out in the traditional way, without the use of mobile devices. At the end of the study, it was observed that the students' attitudes towards mathematics were similar. However, in the control group, students' enjoyment declined significantly. With respect to learning, the experimental group showed greater improvement than the control group (Fabian, Topping, \& Barron, 2018).

In 2015, the PISA exam (Program for International Student Assessment) was given to 305,414 15-year-old students in 11,075 schools across 44 countries. The exam consists of sections testing reading, mathematics, and science. A questionnaire on the use of technology was also given. The information provided by these instruments was analyzed by $\mathrm{Hu}$, Gong, Lai, and Leung (2018), who found a positive relationship between the availability of technology in the school and academic success. In contrast, the relationship was negative when there was technology at home. They also determined that technology skills had a more positive influence on academic performance than technology use and access.

A study carried out by Kiru, Doabler, Sorrells, and Cooc (2017) analyzed 19 interventions in which technology was used for teaching mathematics to K-12 students who had learning deficiencies in mathematics or who were in danger of having them. For the majority of the studies the results were positive. Moreover, they propose including opportunities for practicing with feedback. There have, however, been few studies which incorporate detailed demonstrations and explanations of the exercises.

Young, Gorumek, and Hamilton (2018) explored the effectiveness of the use of technology in teaching mathematics. Their research consisted of 18 meta-analyses carried out between 1986 and 2014 with students from different educational levels. They discovered that academic achievement in mathematics varied to different degrees, from little to greatly. In addition, they found that essential elements for the effectivity of the incorporation of technology in learning should take into account both the academic level of the students, as well as the duration and function it would have in the teaching-learning process.

Finally, one study looked at 24 articles published between 2011 and 2017 in which technology was used for teaching at the university level. The results showed that the use of technology along with traditional teaching had a positive impact on students', teachers', and the universities' educational experience. In turn, they determined that technology allowed students to work independently, increasing communication and collaboration, with greater access to information, and improved confidence in evaluations (Tawafak, Romli, bin Abdullah Arshah, \& Almaroof, $2018)$.

\section{Methodology}

The present research is a quantitative cross-sectional study, since data was collected at a single moment in order to describe variables, as well as to analyze their incidence or interrelation at a given time. An analysis was carried out of the impact on students' academic achievement when using technology for learning mathematics.

The didactic strategy with technology consisted of virtual practices. That is, on-line activities related to the subject of mathematics at undergraduate level. The students attended classes on the subject in which traditional teaching methods were employed, and in addition could carry out virtual practices to strengthen their learning.

The virtual practices were developed for the subject Fundamentals of Mathematics. This subject was created to address the deficiency identified in first year students at the university. The objective of the subject Fundamentals of Mathematics is to standardize students' knowledge of the elemental subjects of Mathematics. Moreover, the indices of failure are high, even though the knowledge corresponds to concepts studied in high school. The motivation of the use of virtual practices in this subject was to provide the students with another alternative for studying what they learned in class with the teacher and to give them the opportunity to continue the academic program with a better performance and understanding of the subject. The students had the choice of studying the subjects seen in class on their own or carrying out the virtual practices.

The subject Fundamentals of Mathematics is offered in the first semester of the Engineering programs at the Instituto Tecnológico de Sonora. All students registered for the Fundamentals of Mathematics course in the semesters of August-December 2018 and January-May 2019 were invited to participate. In all, 563 students were invited to participate in the virtual practices during the August-December 2018 semester, and 581 during the January-May 2019 semester.

The practices were designed so the student could carry them out autonomously in any space with a computer within the university. Each virtual practice began by presenting the objective and then offered an educational video 
explaining the subject. After watching the video, the student carried out the exercises, which allowed for immediate feedback. If the mathematical concept presented was very complicated, it was divided into various videos and specific exercises. The average time allotted for each practice was 30 minutes. However, the student could stop and back the video and the exercises up to fit his needs.

The subjects covered by the virtual practices included Arithmetic (numbers on a number line, ranking of operations, operations with fractions) and Algebra (algebraic expressions, remarkable products, factorization, fundamental operations with rational expressions, linear equations, systems of linear equations, quadratic equations, circumference, systems of linear inequalities and quadratics, absolute value, trigonometry and logarithms).

Data was collected at the beginning and end of each semester. The information corresponding to the number of students invited to carry out virtual practices, the number of students who chose to carry out the practices or not, the number that passed the course Fundamentals of Mathematics, and the number of practices carried out made up the variables of the study.

The statistical analysis was carried out using contingency tables to determine the independence of the variables of the study. The statistical test was the Chi-square test considering .001 of significance. The data was analyzed using Minitab 14 software.

The following procedure was used in the present study:

1. The virtual practices for the subjects of the course of Fundamentals of Mathematics were developed.

2. At the beginning of the August-December 2018 semester a diagnostic exam was given to the students registered on the course of Fundamentals of Mathematics. Based on this exam, the students who received a grade of four or less (on a 1 to 10 scale) were identified and these students were invited to use the virtual practices.

3. For the January-May 2019 semester, all the students registered on the course Fundamentals of Mathematics were invited to use the virtual practices.

4. The students carried out the virtual practices throughout the semester in a computer room within the university's premises.

5. The data was collected at the end of the semester.

6. The information was analyzed using statistical software.

\section{Results}

The first research question asks to what extent the implementation of the didactic strategy consisting of virtual practices contributes to the learning of mathematics. In order to answer this question, the objective of determining the contribution of virtual practice to the learning of mathematics were established.

To attain this objective, the variables were defined with dichotomic values: Academic Achievement Variable (AA) and Was invited to carry out Virtual Practices Variable (IP) were assigned the values described in Table 1.

Table-1. Definition of variable with dichotomic values.

\begin{tabular}{c|l|l|}
\hline $\begin{array}{c}\text { Dichotomic } \\
\text { Value }\end{array}$ & Academic Achievement Variable (AA) & $\begin{array}{l}\text { Was invited to carry out Virtual } \\
\text { Practices Variable (IP) }\end{array}$ \\
\hline $\mathrm{O}$ & $\begin{array}{l}\text { The student did not pass the Fundamentals } \\
\text { of Mathematics course }\end{array}$ & $\begin{array}{l}\text { The student did not attend the virtual } \\
\text { practices }\end{array}$ \\
\hline 1 & $\begin{array}{l}\text { The student passed the Fundamentals of } \\
\text { Mathematics course }\end{array}$ & $\begin{array}{l}\text { The student attended and carried out the } \\
\text { virtual practices }\end{array}$ \\
\hline
\end{tabular}

The objective of the contingency table is to identify whether there is interdependence between the variables Academic Achievement and was invited to carry out Virtual Practices. The following hypotheses were established for this purpose:

$H_{\text {o: }}$ The AA Variables (Row) and IP (Column) are independent.

$H_{I}$ : The AA Variables (Row) and IP (Column) are dependent.

In Table 2 we can see the data corresponding to the contingency table for the students enrolled in the AugustDecember 2018 semester.

Table-2. Contingency Table of the variables Academic Achievement and Was invited to carry out the Virtual Practices for the August-December 2018 semester.

\begin{tabular}{c|c|c|c}
\hline $\begin{array}{c}\text { Dichotomic } \\
\text { Value }\end{array}$ & o & $\mathbf{1}$ & All \\
\hline o & 307 & 48 & 355 \\
\hline & 86.48 & 13.52 & 100.00 \\
\hline & 78.12 & 28.24 & 63.06 \\
\hline & 54.53 & 8.53 & 63.06 \\
\hline 1 & 86 & 122 & 208 \\
\hline & 41.35 & 58.65 & 100.00 \\
\hline & 21.88 & 71.76 & 36.94 \\
\hline All & 15.28 & 21.67 & 36.94 \\
\hline & 393 & 170 & 563 \\
\hline & 69.80 & 30.20 & 100.00 \\
\hline & 100.00 & 100.00 & 100.00 \\
\hline & 69.80 & 30.20 & 100.00 \\
\hline
\end{tabular}

The 563 students who according to the diagnostic test had obtained a grade of 4 or less (on a 1-10 scale) were invited to carry out the virtual practices during the August-December 2018 semester. With respect to the Was invited to carry out the Virtual Practices Variable, of the 563 students, 208 (36.94\%) attended the virtual practices, and $355(63.06 \%)$ did not. 
In reference to the Academic Achievement Variable, of the 563 students, $170(30.20 \%)$ passed the Fundamentals of Mathematics course and 393 (69.80\%) did not pass the course. However, of the 170 students who passed the Fundamentals of Mathematics course, $122(71.76 \%)$ had attended and carried out the Virtual Practice and $48(28.24 \%)$ had not attended.

With respect to failing the course and the variable Was invited to carry out the Virtual Practices, of the 393 students who did not pass the Fundamentals of Mathematics course, 86 (21.88\%) attended the virtual practices and $307(78.12 \%)$ did not attend the virtual practices.

The statistical Chi-square test (126.748) considering significance of less than .001 indicated rejection of the null hypothesis, which shows that there is independence between the Academic Achievement and Was invited to carry out the virtual Practices variables. Passing or not passing the Fundamentals of Mathematics course depended on the student's attending the virtual practices. A higher percentage of students who attended and carried out the virtual practices passed the Fundamentals of Mathematics course than those who did not attend the virtual practices.

Table 3 shows the data which corresponds to the contingency table for students enrolled in the January-May 2019 semester.

Table-3. Contingency table for the variables Academic Achievement and Was invited to carry out the virtual Practices for the January-May 2019 semester.

\begin{tabular}{c|c|c|c}
\hline Dichotomic Value & $\mathbf{0}$ & $\mathbf{1}$ & All \\
\hline O & 279 & 49 & 328 \\
\hline & 85.06 & 14.94 & 100.00 \\
\hline & 68.05 & 28.65 & 56.45 \\
\hline 1 & 48.02 & 8.43 & 56.45 \\
\hline & 131 & 122 & 253 \\
\hline & 51.78 & 48.22 & 100.00 \\
\hline & 31.95 & 71.35 & 43.55 \\
\hline & 22.55 & 21.00 & 43.55 \\
\hline & 410 & 171 & 581 \\
\hline & 70.57 & 29.43 & 100.00 \\
\hline & 100.00 & 100.00 & 100.00 \\
\hline & 70.57 & 29.43 & 100.00 \\
\hline
\end{tabular}

For the January-May 2019 semester 581 students who were enrolled in the Fundamentals of Mathematics course were invited to carry out the virtual practices. With respect to the variable Was invited to carry out the Virtual Practices, of the 581 students, 253 (43.55\%) attended and carried out the virtual practice and 328 (56.45\%) did not attend.

With respect to the Academic Achievement variable, of the 581 students, 171 (29.43\%) passed the Fundamentals of Mathematics course and $410(70.57 \%)$ failed the course. However, of the 171 students who passed the Fundamentals of Mathematics course, 122 (71.35\%) had attended the virtual practices while $49(28.65 \%)$ had not attended.

The relation between not passing the course and the Was invited to carry out the Virtual Practices variable yields that of the 410 students who did not pass the Fundamentals of Mathematics course, $131(31.95 \%)$ had attended the virtual practices and $279(68.05 \%)$ had not attended the virtual practices.

The statistical Chi-square test (76.176) considering significance of less than .001 indicated rejection of the null hypothesis, which shows that there is independence between the Academic Achievement and Was invited to carry out the Virtual Practices variables. A higher percentage of students who had attended and carried out the virtual practices passed the Fundamentals of Mathematics course than those who had not attended the virtual practices.

With respect to the results of students who passed and had attended the virtual practices during the AugustDecember 2018 and January-May 2019 semesters, a test of the difference of ratios between the two groups was carried out. The variables ratio of students who passed and had attended the Virtual Practices during the AugustDecember 2018 semester $\left(p_{1}\right)$ and the ratio of students who passed the course and had attended the virtual Practices during the January-May 2019 semester $\left(p_{2}\right)$ were established. The hypotheses which were formulated are:

$\mathrm{H}_{0}: p_{1}=p_{2}$

$\mathrm{H}_{1}: p_{1} \neq p_{2}$

The level of significance was .05 with a critical value of $z= \pm 1.96$ with bilateral contrast. The calculated statistical $z$ was .4229 and thus the null hypothesis which establishes that the ratio of students who passed the course during the August-December 2018 was equal to the ratio of students who passed the course during the January-May 2019 semester was accepted.

The second research question examines the effect of the didactic strategy of virtual practices on students' academic achievement. To this end, the objective established was to identify the effect that virtual practices had on students' academic achievement.

In keeping with this objective, a correlation analysis was carried out between the variables Grade in the Fundamentals of Mathematics course and the number of virtual practices carried out by the student, in order to determine whether there was a linear dependence between the two variables. Table 4 presents the results of the correlation analysis for the August-December 2018 and January-May 2019 semesters.

Table-4. Correlation analysis between the variable Grade in the Fundamentals of Mathematics course and the number of virtual practices carried out for the August-December 2018 and January-May 2019 semesters.

\begin{tabular}{c|c|c}
\hline Semester & Pearson product-moment correlation coefficient & $\boldsymbol{p}$ \\
\hline August-December 2018 & .517 & $<.001$ \\
\hline January-May 2019 & .382 & $<.001$ \\
\hline
\end{tabular}


For the August-December 2018 semester, the results show that there was dependence between the two variables. The Pearson product-moment correlation coefficient .517 with $p<.001$ means that the greater the number of practices a student carried out, the higher the grade obtained in the Fundamentals of Mathematics course.

Similarly, for the January-May 2019 semester the findings show that there is dependence between the two variables. The Pearson product-moment correlation coefficient of .382 with $p<.001$ shows that the greater the number of practices a student carried out, the higher the grade obtained in the Fundamentals of Mathematics course.

For both semesters, August-December 2018 and January-May 2019, dependence was found between the variables Number of virtual practices carried out by a student and the Grade he obtained in the Fundamentals of Mathematics course with <.001 significance. The relation between the variables is positive: as one variable increases, so does the other: the more virtual practices a student carried out, the higher the grade in the Fundamentals of Mathematics course.

\section{Discussion}

The didactic strategy of virtual practices we implemented for the Fundamentals in Mathematics course for university students has resulted in better grades on the course and more passing grades for students. These results are in keeping with the evidence obtained by Davies et al. (2017) who point out that learning based on technology can improve academic results. Similarly, Outhwaite et al. (2019) found that the integration of technology into the mathematics curriculum makes for better learning.

In addition, Tawafak et al. (2018) found that the use of technology in conjunction with traditional teaching had a positive impact on learning. This is in keeping with the findings of the present research, where technology is used in addition to traditional teaching.

The inclusion of opportunities to solve exercises with immediate feedback was a key characteristic in the construction of the virtual practices and this aspect is considered to be a factor which influences the positive results, as described by Kiru et al. (2017). The opportunity to immediately identify their shortcomings when solving a mathematical problem increases students' self-confidence, thus eliminating a barrier which blocks learning (Bettinger et al., 2018; Boaler, 2016).

The availability of technology for teaching is a variable which is positively related to academic success (Hu et al., 2018). However, the way in which technology is included in learning is what should be further investigated in order to obtain better results, according to John (2008), as well as Davies et al. (2017). For the present research, the inclusion of technology was through virtual practices and this method has been shown to be effective in the learning of mathematics through self-learning by university students.

\section{Conclusions}

The present study presented two research questions and based on these defined two objectives. The first objective was to determine the contribution a didactic strategy using virtual practices had to university students' learning of mathematics. To this end, the students who had enrolled in the Fundamentals of Mathematics course during two different semesters were invited to carry out virtual practices.

By means of contingency tables it was established that a higher percentage of students who had carried out the virtual practices in both semesters (August-December 2018 and January-May 2019) passed the Fundamentals of Mathematics course than those who had not attended the virtual practices. Therefore, we can affirm that the virtual practices contributed to a greater number of students passing the Fundamentals of Mathematics course.

With respect to the second objective of the research which sought to identify the effect the didactic strategy consisting of virtual practices had on students' academic achievement, a correlation analysis was carried out. The Pearson product-moment correlation coefficient, for both semesters, shows a positive dependence between the variables of the students' grades in the Fundamentals of Mathematics course and the number of practices the students carried out. The relation of dependence indicates that the more practices a student carried out, the higher the grade obtained in the Fundamentals of Mathematics course.

\section{References}

Bettinger, E., Ludvigsen, S., Rege, M., Solli, I., \& Yeager, D. (2018). Increasing perseverance in math: Evidence from a field experiment in Norway. Journal of Economic Behavior \& Organization, 146, 1-15. Available at: https://doi.org/10.1016/j.jebo.2017.11.032.

Boaler, J. (2016). Mathematical Mindsets: Unleashing students' potential through creative math, inspiring messages and innovative teaching. San Francisco, CA: John Wiley \& Sons.

Davies, S., Mullan, J., \& Feldman, P. (2017). Rebooting learning for the digital age: What next for technology enhanced higher education? Oxford: Oxuniprint.

Fabian, K., Topping, K. J., \& Barron, I. G. (2018). Using mobile technologies for mathematics: Effects on student attitudes and achievement. Educational Technology Research and Development, 66(5), 1119-1139. Available at: https://doi.org/10.1007/s 11423-018-9580-3.

Fox-Turnbull, W. (2017). Teaching and learning in technology: Section introduction. In M. J. de Vries (Ed.), Handbook of Technology Education (pp. 441-445). Cham: Springer International Handbooks of Education.

Hassler, M., Klingberg, T., \& Ghaderi, A. (2018). Short and long-term effects of a mathematics tablet intervention for low performing second graders. Journal of Educational Psychology, $110(8), 1127-1148$. Available at: http://dx.doi.org/10.1037/edu0000264.

Henderson, M., Selwyn, N., \& Aston, R. (2017). What works and why? Student perceptions of 'useful' digital technology in university teaching and learning. Studies in Higher Education, 42(8), 1567-1579. Available at: https://doi.org/10.1080/03075079.2015.1007946.

Hu, X., Gong, Y., Lai, C., \& Leung, F. (2018). The relationship between ICT and student literacy in mathematics, reading, and science across 44 countries: A multilevel analysis. Computers \& Education, 125, 1-13. Available at: https://doi.org/10.1016/j.compedu.2018.05.021.

John, P. W., S. (). . (2008). The digital classroom. Harnessing technology for the future of learning and teaching. London: David Fulton Publishers.

Kiru, E., Doabler, C., Sorrells, A., \& Cooc, N. (2017). A synthesis of technology-mediated mathematics interventions for students with or at risk for mathematics learning disabilities. Journal of Special Education Technology, 33(2), 111-123. Available at: https://doi.org/10.1177/0162643417745835.

Kollosche, D. (2018). Social functions of mathematics education: A framework for socio-political studies. Educational Studies in Mathematics, 98(3), 287-303. Available at: https://doi.org/10.1007/s 10649-018-9818-3. 
Outhwaite, L. A., Faulder, M., Gulliford, A., \& Pitchford, N. J. (2019). Raising early achievement in math with interactive apps: A randomized control trial. Journal of Educational Psychology, 111(2), 284-298. Available at: http://dx.doi.org/10.1037/eduo000286.

Pellegrini, M., Lake, C., Inns, A., \& Slavin, R. (2018). Effective programs in elementary Mathematics: A best-evidence synthesis. Annual meeting of the Society for Research on Educational Effectiveness (pp. 1-82). Washington, DC.: Johns Hopkins University School of Education.

Pitta-Pantazi, D., \& Leikin, R. (2018). Chapter 9. Mathematical potential, creativity and talent. En T. Dreyfus, M. Artigue, D. Potari, S. Prediger y K. Ruthven (Eds.), Developing Research in Mathematics Education. Twenty years of communication, cooperation and collaboration in Europe (pp. 128-140). London: Routledge.

Tawafak, R. M., Romli, A. B., bin Abdullah Arshah, R., \& Almaroof, R. A. S. (2018). Assessing the impact of technology learning and assessment method on academic performance. EURASIA Journal of Mathematics, Science and Technology Education, 14(6), 2241-2254. Available at: https://doi.org/10.29333/ejmste/87117.

UNESCO. (2015). Education 2030: Incheon Declaration and Framework for action for the implementation of Sustainable Development Goal 4: Ensure inclusive and equitable quality education and promote lifelong learning opportunities for all. World Educators Forum of the United Nations Educational, Scientific and Cultural Organization (pp. 1-83). Paris, France: UNESCO.

Young, J., Gorumek, F., \& Hamilton, C. (2018). Technology effectiveness in the mathematics classroom: a systematic review of meta-analytic research. Journal of Computers in Education, 5(2), 133-148. Available at: https://doi.org/10.1007/s40692-018-0104-2. 